\title{
Indocyanine Green Plasma Disappearance Rate During the Anhepatic Phase of Orthotopic Liver Transplantation
}

\author{
Lukas Bruegger • Peter Studer • Stefan W. Schmid • \\ Gunther Pestel • Juerg Reichen • Christian Seiler • \\ Daniel Candinas • Daniel Inderbitzin
}

Received: 17 May 2007 / Accepted: 14 September 2007 / Published online: 25 October 2007

(C) 2007 The Society for Surgery of the Alimentary Tract

\begin{abstract}
Non-invasive pulse spectrophotometry to measure indocyanine green (ICG) elimination correlates well with the conventional invasive ICG clearance test. Nevertheless, the precision of this method remains unclear for any application, including small-for-size liver remnants. We therefore measured ICG plasma disappearance rate (PDR) during the anhepatic phase of orthotopic liver transplantation using pulse spectrophotometry. Measurements were done in 24 patients. The median PDR after exclusion of two outliers and two patients with inconstant signal was $1.55 \% / \mathrm{min}(95 \%$ confidence interval $[\mathrm{CI}]=0.8-2.2$ ). No correlation with patient age, gender, body mass, blood loss, administration of fresh frozen plasma, norepinephrine dose, postoperative albumin (serum), or difference in pre and post transplant body weight was detected. In conclusion, we found an ICG-PDR different from zero in the anhepatic phase, an overestimation that may arise in particular from a redistribution into the interstitial space. If ICG pulse spectrophotometry is used to measure functional hepatic reserve, the verified average difference from zero $(1.55 \% / \mathrm{min})$ determined in our study needs to be taken into account.
\end{abstract}

Keywords Indocyanine green · Pulse spectrophotometry · Orthotopic liver transplantation · Small-for-size liver remnant

Presented at the Forty-eighth Annual Meeting of The Society for Surgery of the Alimentary Tract, Washington DC, May 19-24, 2007 (poster presentation).

L. Bruegger $\cdot$ P. Studer $\cdot$ S. W. Schmid $\cdot$ C. Seiler $\cdot$

D. Candinas $\cdot D$. Inderbitzin $(\bowtie)$

Department of Visceral and Transplant Surgery,

University Hospital Bern,

CH-3010 Bern, Switzerland

e-mail: daniel.inderbitzin@insel.ch

G. Pestel

Institute of Anaesthesiology, University Hospital Bern,

Bern, Switzerland

J. Reichen

Institute of Clinical Pharmacology, University Hospital Bern,

Bern, Switzerland

\section{Introduction}

In addition to the expected volume of the liver remnant, ${ }^{1}$ quantitative (or "dynamic") liver function tests have been used to predict the risk of hepatic failure after liver resection. ${ }^{2,3}$ Indocyanine green (ICG) is a nontoxic dye extracted exclusively by hepatic parenchymal cells without enterohepatic circulation and excreted entirely into the bile. ${ }^{2,4}$ The ICG elimination test was originally invented to determine hepatic blood flow, but it is in fact an integrative measure of both hepatic perfusion and excretory function. ${ }^{5-7}$ Therefore, ICG elimination testing has been used for the past 20 years in the context of hepatic resection ${ }^{8}$ and to assess liver functional reserve in hepatic injury and septic states; in addition, it was found to be as accurate as more complex scores (e.g., APACHE II and SAPS II) with respect to outcome prediction..$^{9-11}$ Moreover, ICG elimination tests are intended to determine the suitability of a potential donor liver and to recognize early graft dysfunction resulting from, for example, primary delayed or nonfunction of the graft, technical complications, and acute or chronic graft rejection in the transplant setting. ${ }^{12-14}$ 
Table 1 The Demographic Data of all Patients

\begin{tabular}{|c|c|c|c|c|}
\hline$N$ & Diagnosis & Age (years) & Gender & BMI $\left(\mathrm{kg} / \mathrm{m}^{2}\right)$ \\
\hline 1 & $\mathrm{CHC}$ & 64 & $\mathrm{~F}$ & 25.8 \\
\hline 2 & $\mathrm{CHC} / \mathrm{HCC}$ & 49 & M & 28.0 \\
\hline 3 & $\mathrm{CHC}$ & 47 & M & 27.0 \\
\hline 4 & $\mathrm{CHC} / \mathrm{ETC}$ & 39 & $\mathrm{~F}$ & 25.1 \\
\hline 5 & $\mathrm{CHB} / \mathrm{HCC}$ & 48 & M & 27.9 \\
\hline 6 & NASH & 53 & M & 46.0 \\
\hline 7 & $\mathrm{CHC} / \mathrm{HCC}$ & 66 & M & 20.8 \\
\hline 8 & $\mathrm{CHC} / \mathrm{CHB}$ & 50 & $\mathrm{~F}$ & 29.3 \\
\hline 9 & IP & 40 & $\mathrm{~F}$ & 20.9 \\
\hline 10 & $\mathrm{CHC}$ & 62 & M & 29.4 \\
\hline 11 & $\mathrm{PBC}$ & 63 & $\mathrm{~F}$ & 22.1 \\
\hline 12 & $\mathrm{CC}$ & 56 & $\mathrm{~F}$ & 24.0 \\
\hline 13 & ETC & 55 & M & 24.1 \\
\hline 14 & MCLC & 62 & $\mathrm{~F}$ & 25.5 \\
\hline 15 & $\mathrm{CHC}$ & 57 & M & 34.8 \\
\hline 16 & ETC & 53 & $\mathrm{~F}$ & 24.7 \\
\hline 17 & IP & 57 & $\mathrm{~F}$ & 25.0 \\
\hline 18 & $\mathrm{CHB} / \mathrm{HCC}$ & 49 & $\mathrm{~F}$ & 30.4 \\
\hline 19 & $\mathrm{CHC} / \mathrm{HCC}$ & 68 & M & 27.0 \\
\hline 20 & $\mathrm{PBC}$ & 59 & $\mathrm{~F}$ & 19.0 \\
\hline 21 & $\mathrm{AIH}$ & 69 & $\mathrm{~F}$ & 22.0 \\
\hline 22 & UC & 61 & M & 24.0 \\
\hline 23 & $\mathrm{CHB}$ & 41 & M & 28.0 \\
\hline 24 & NASH & 59 & $\mathrm{~F}$ & 29.0 \\
\hline Median $^{\mathrm{a}}$ & - & $56(49-62)$ & - & $26.4(24.7-28.0)$ \\
\hline
\end{tabular}

$C H C$ : chronic hepatitis $\mathrm{C}, C H B$ : chronic hepatitis B, ETC: ethyltoxic cirrhosis, PBC: primary biliary cirrhosis, $N A S H$ : nonalcoholic steatohepatitis cirrhosis, $C C$ : cryptogenic cirrhosis, MCLC: multiple congenital liver cysts, IP: intoxication with paracetamol, AIH: autoimmune hepatitis, $U C$ : diagnosis unclear, $F$ : female, $M$ : male, $B M I$ : body mass index

${ }^{a}$ Median is without patients 11 and 15 (the outliers), and 9 and 12 (unstable signal). Values in parentheses are the $95 \% \mathrm{CI}$.

Noninvasive pulse spectrophotometry ${ }^{15}$ allows the monitoring of appearance and disappearance of ICG by a photometric device performing transcutaneous measurements in real time. It is supposed to correlate well with the conventional invasive ICG clearance test. ${ }^{16-18}$ In the postoperative course, a plasma disappearance rate (PDR) $>5.0 \% /$ min seems to indicate hepatic recovery after extended liver resections. ${ }^{19}$ In particular, in small-for-size liver remnants $(<0.8 \% \text { of body weight })^{1,20}$ and in fulminant hepatic failure, real-time prognostic tests are urgently needed as a decision aid for indication of artificial liver support systems like the molecular adsorbent recirculating system (MARS). ${ }^{21,22}$ To date, clear indications for the postoperative initiation of MARS treatment and criteria for the discontinuation of therapy have not been established. ${ }^{19}$

Unfortunately, data are thus far lacking about the precision of ICG elimination tests in situations with limited residual hepatic functional reserves. ${ }^{5,7}$ We sought to test the accuracy of ICG-PDR measurements by pulse spectropho- tometry in a situation without hepatic perfusion and/or excretion and thus tested the hypothesis that ICG-PDR is zero or close to zero in patients during the anhepatic phase of orthotopic liver transplantation (OLT).

\section{Materials and Methods}

A total of 24 consecutive patients who underwent OLT between March 2005 and April 2007 in our institution were included in the current study after giving informed consent (institutional approval: 1.05.01.30.-17).

During the anhepatic phase of OLT, noninvasive measurement of ICG-PDR was performed in all patients. We rapidly injected $25 \mathrm{mg}$ of ICG (Monopeak Indocyanine Green, SERB SA, Paris) in a constant volume of $10 \mathrm{ml}$ saline via the jugular catheter. Urine concentrations of ICG were measured in four patients after ICG injection.

\section{ICG Pulse Spectrophotometry}

Pulse-dye densitometry (LiMON, Pulsion Medical Systems, Munich, Germany) was used for transcutaneous noninvasive measurement of the blood ICG concentration. During the first 5-10 min after intravenous injection, ICG concentrations were monitored at every pulse interval via pulse spectrophotometry. ICG-PDR as a relative measure describes fading of the initial ICG concentration (normalized to $100 \%$ ) and is expressed as percentage change over time. Because ICG-PDR $=100 \times k=100 \times \ln 2 / t^{1 / 2}, k$ (elimination rate constant) and $t^{1 / 2}$ (half-life), which have been

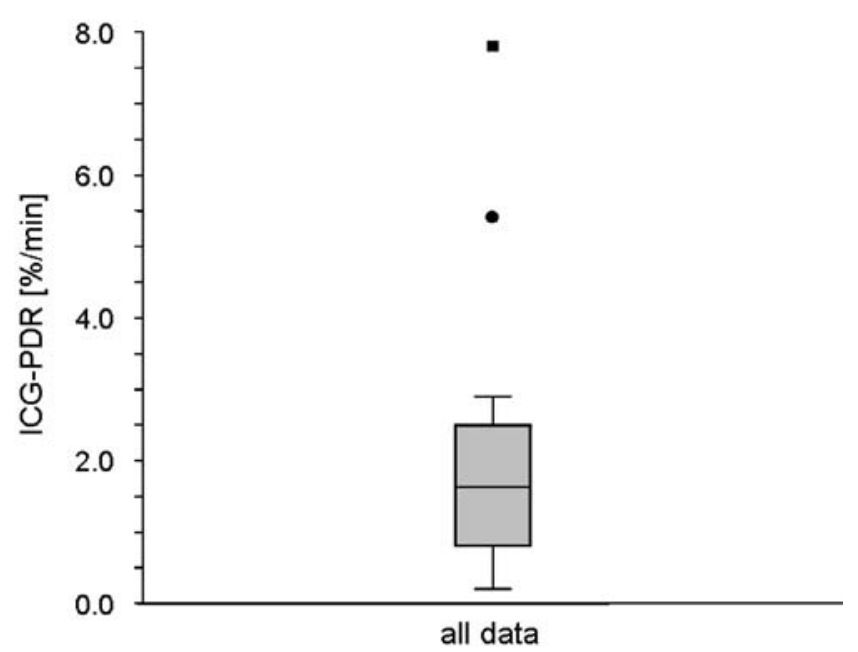

Figure 1 The indocyanine green plasma disappearance rate (ICGPDR) values during the anhepatic phase of orthotopic liver transplantation in 22 patients are shown. The extent of the box indicates the 25 th and 75 th percentiles (inner-quartile range). The line inside the box shows the value of the 50th percentile (median). Capped bars indicate the last observations that are within the inner fence (25th or 75th, respectively, \pm 1.5 times the inner-quartile range), and symbols mark outliers (beyond inner fence). 
Table 2 Results of Spectrophotometry and Possible Influencing Parameters

\begin{tabular}{|c|c|c|c|c|c|c|c|}
\hline$N$ & $\begin{array}{l}\text { ICG PDR } \\
(\% / \mathrm{min})\end{array}$ & $\mathrm{PCS}^{\mathrm{a}}$ & $\mathrm{NE}^{\mathrm{b}}(\mu \mathrm{g} / \mathrm{h})$ & Blood loss $^{c}(\mathrm{ml})$ & $\mathrm{FFP}^{\mathrm{d}}$ (unit) & $\operatorname{Albumin}^{\mathrm{e}}(\mathrm{g} / \mathrm{l})$ & $\Delta$ weight $^{\mathrm{f}}(\mathrm{kg})$ \\
\hline 1 & 2.2 & Yes & 1,200 & 1,000 & 0 & 26 & 4.3 \\
\hline 2 & 2.6 & No & 0 & 300 & 0 & 25 & 3.8 \\
\hline 3 & 0.2 & Yes & 1,000 & 1,000 & 4 & 30 & 0.2 \\
\hline 4 & 2.5 & Yes & 800 & 2,000 & 6 & 24 & 0.2 \\
\hline 5 & 0.8 & No & 400 & 300 & 0 & 25 & 4.1 \\
\hline 6 & 1.0 & No & 1,500 & 2,500 & 22 & 24 & -1.0 \\
\hline 7 & 0.9 & No & 0 & 500 & 0 & 43 & 4.2 \\
\hline 8 & 1.9 & Yes & 1,200 & 1,500 & 2 & 19 & 8.0 \\
\hline 9 & i.s. & No & 1,000 & 200 & 0 & n.a. & n.a. \\
\hline 10 & 2.5 & Yes & 800 & 1,700 & 4 & 18 & -0.9 \\
\hline 11 & 5.4 & Yes & 600 & 150 & 0 & 10 & 3.7 \\
\hline 12 & i.s. & Yes & 400 & 1,200 & 3 & n.a. & n.a. \\
\hline 13 & 0.8 & Yes & 240 & 1,700 & 0 & 25 & 0.5 \\
\hline 14 & 2.9 & Yes & 140 & 1,200 & 0 & 20 & 5.6 \\
\hline 15 & 7.8 & Yes & 80 & 5,000 & 9 & 28 & -0.2 \\
\hline 16 & 0.2 & Yes & 0 & 2,250 & 0 & 25 & 9.1 \\
\hline 17 & 2.0 & No & 100 & 1,300 & 0 & 21 & 0.7 \\
\hline 18 & 2.5 & Yes & 0 & 1,000 & 0 & 21 & 0.8 \\
\hline 19 & 1.5 & No & 600 & 2,300 & 0 & 22 & -3.0 \\
\hline 20 & 0.6 & Yes & 100 & 800 & 5 & 21 & n.a. \\
\hline 21 & 1.0 & Yes & 200 & 1,000 & 0 & 19 & 5.6 \\
\hline 22 & 1.7 & Yes & 360 & 500 & 8 & 27 & 0.7 \\
\hline 23 & 1.6 & Yes & $50 \mathrm{PE}$ & 2,300 & 5 & 24 & 3.1 \\
\hline 24 & 0.7 & Yes & 180 & 3,000 & 5 & 21 & 1.1 \\
\hline Median $^{\mathrm{g}}$ & $\begin{array}{l}1.55 \\
(0.8-2.2)\end{array}$ & n.a. & $\begin{array}{l}240 \\
(100-800)\end{array}$ & $\begin{array}{l}1,250 \\
(1,000-2,000)\end{array}$ & $0(0-5)$ & $24(21-25)$ & $1.1(0.2-4.2)$ \\
\hline $\begin{array}{l}\text { Correlation } \\
\text { with ICG-PDR } \\
\left(R^{2}\right)^{\mathrm{h}}\end{array}$ & n.a. & $p>0.05^{\mathrm{i}}$ & $\begin{array}{l}0.003 \\
\quad(p>0.05)^{\mathrm{j}}\end{array}$ & $0.023(p>0.05)^{\mathrm{j}}$ & $0.021(p>0.05)^{\mathrm{j}}$ & $0.112(p>0.05)^{\mathrm{j}}$ & $0.008(p>0.05)$ \\
\hline
\end{tabular}

$I C G-P D R$ : indocyanine green plasma disappearance rate, i.s.: instable signal, $P C S$ : portacaval shunt, $N E$ : norepinephrine, $P E$ : phenylephrine, FFP: fresh frozen plasma, n.a.: not available

${ }^{a}$ Application of PCS during anhepatic phase.

${ }^{\mathrm{b}}$ Application of NE dose during anhepatic phase.

${ }^{\mathrm{c}}$ Blood loss from the beginning of the operation until the anhepatic phase.

${ }^{d}$ Administered units of FFP from the beginning of the operation until the anhepatic phase.

${ }^{\mathrm{e}}$ Albumin (serum) on third postoperative day.

${ }^{\mathrm{f}} \Delta$ weight $=$ difference of body weight before and 3 days after the operation.

${ }^{\mathrm{g}}$ Median is without patients 11 and 15 (the outliers), and 9 and 12 (unstable signal). Values in parentheses are the $95 \% \mathrm{CI}$.

${ }^{\mathrm{h}}$ Coefficient of determination.

${ }^{\mathrm{i}}$ Wilcoxon rank-sum test.

${ }^{\mathrm{j}} t$-test.

used in earlier publications, can easily be derived. Normal values for ICG blood clearance are considered to be $>18 \% /$ min. $^{6}$

\section{Spectrophotometric Measurement of ICG in Urine}

Urine was collected for 115 to 210 min after injection of the dye. Samples were afterwards centrifuged. The ICG concentration in the supernatant was read against the blank at $800 \mathrm{~nm}$ on a Perkin Elmer Lambda 15 (Waltham, MA, USA) photometer.
Renal ICG-PDR (ICG-PDR ${ }_{\mathrm{r}}$ ) was calculated from the absolute ICG amount in urine $(u)$ collected over a time period $(t)$ after the injection of a dose $(d)$ according to the equation:

ICG-PDR $_{\mathrm{r}}=100 \times\left(1-((d-u) / d)^{1 / t}\right)$

\section{Statistical Analysis}

Data are presented as the median with the $95 \% \mathrm{CI}$ in parentheses. Values beyond the inner fence (25th or 75 th 


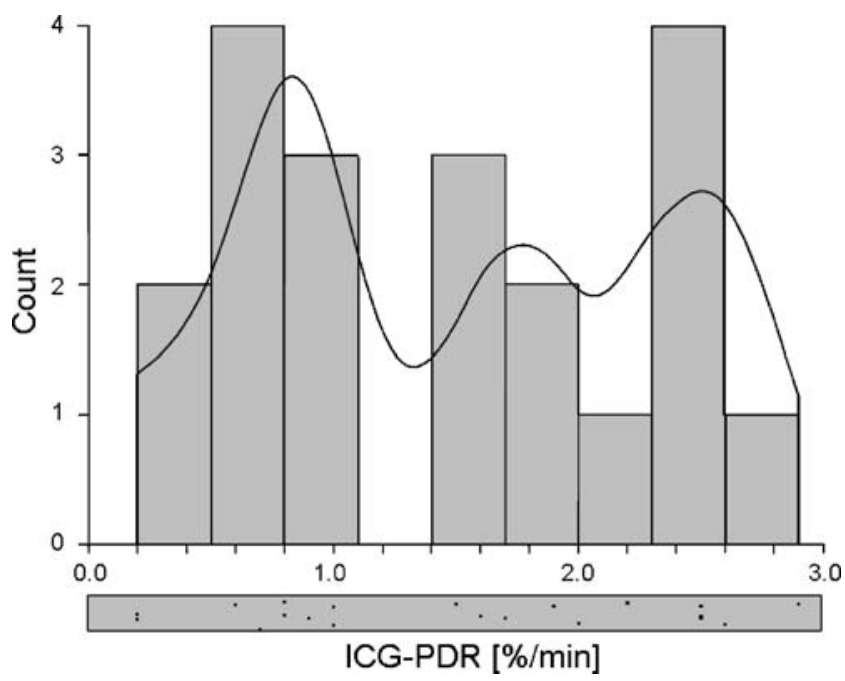

Figure 2 Histogram of ICG-PDR values with density trace (black line) and dot plot along the horizontal axis (raw data).

percentiles, respectively, \pm 1.5 times the inner-quartile range) were defined as outliers. Normality of data was proved with the Kolmogorov-Smirnov and D'Agostino Kurtosis tests. Descriptive statistics, group comparisons (Wilcoxon rank-sum test), and linear regressions were made using statistical software (NCSS 2004, Kaysville, Utah, USA). To test the linear regression, the coefficient of determination $\left(R^{2}=\right.$ square of the correlation coefficient) was determined and its significance tested with a $t$-test.

\section{Results}

The indications for OLT and the demographic data of all 24 patients are shown in Table 1. Two patients had to be excluded from further analysis because of an unstable percutaneous ICG signal.

After exclusion of two outliers as shown in Fig. 1 (ICG$\mathrm{PDR}=5.4 \% / \mathrm{min}$ and $7.8 \% / \mathrm{min}$ ), the median ICG-PDR was $1.55 \% / \mathrm{min}(95 \% \mathrm{CI}=0.8-2.2)$.

We performed univariate linear regression analysis with the following independent variables: norepinephrine during the anhepatic phase of OLT, blood loss, units of fresh frozen plasma given until the anhepatic phase, serum albumin on the third postoperative day, body weight before and 3 days after the operation, the time course of liquid balance (not depicted), and the tidal volume during the anhepatic phase (not depicted). As Table 2 shows, we identified no correlation of any of these variables with ICGPDR $(\% / \mathrm{min})$; all coefficient of determination $\left(R^{2}\right)$ values were close to zero and $p>0.05$. Furthermore, we found no difference in ICG-PDR between the groups with or without application of a temporary portacaval shunt $(p>0.05)$.
The renal ICG-PDR $\mathrm{r}_{\mathrm{r}}$ was found to be minute in comparison to the ICG-PDR values derived from the pulse spectrometer (Fig. 2, Table 3).

\section{Discussion}

Using a commercially available bedside monitor system, we unexpectedly found that ICG-PDR values showed considerable variability and differed from zero in the anhepatic phase of OLT in 22 patients. Of all the examined clinical cofactors, we found no correlation with ICG-PDR. Because neither blood loss nor administration of fresh frozen plasma before the anhepatic phase seemed to influence ICG-PDR, dilution during the measurement as a consequence of volume challenge after hemorrhage does not explain the ICG-PDR values different from zero. Alterations of the otherwise high protein binding of ICG as a consequence of volume or fresh frozen plasma administration are thus also very unlikely as an explanation for our findings. ${ }^{23}$

In addition, the tidal volume and therefore hypocapnia or hypercapnia do not affect ICG elimination by mechanisms other than changes in hepatic flow and hepatic function, as has already been established in an animal model. ${ }^{24}$ Catecholamines and a temporary portacaval shunt seem to influence ICG-PDR only via changes in hepatic perfusion. ${ }^{25,26}$ The extremely low amounts of ICG found in urine in our experiments also exclude renal excretion as a reason for the observed plasma disappearance of ICG. Technical failure because of detecting probe malpositioning and patient movement are excludable because the pulse spectrophotometer system used in this study does not allow measurements with weak or inconsistent signals. Spontaneous decay of ICG is also a rather implausible explanation

Table 3 ICG Measurement in Urine in Four Patients

\begin{tabular}{llll}
\hline $\begin{array}{l}\text { ICG-PDR }^{\mathrm{a}} \\
(\% / \mathrm{min})\end{array}$ & Time $^{\mathrm{b}}(\mathrm{min})$ & ICG in urine & \\
\hline 1 & 115 & 0.050 & $\begin{array}{l}\text { ICG-PDR }_{\mathrm{r}}{ }^{\mathrm{c}} \\
(\% / \mathrm{min})\end{array}$ \\
1.7 & 120 & 0.011 & 0.0017 \\
1.6 & 120 & 0.003 & 0.0004 \\
0.7 & 210 & 0.047 & 0.0001 \\
\hline
\end{tabular}

${ }^{\mathrm{a}}$ ICG-PDR was measured by pulse spectrophotometry (LiMON).

${ }^{\mathrm{b}}$ Urine was collected during roughly (time) $2 \mathrm{~h}$ after ICG injection.

${ }^{\mathrm{c}}$ The total amount of ICG in urine was determined by photospectrometry.

${ }^{d}$ Based on this amount of ICG, the renal ICG-PDR $r$ was then calculated according to the equation described in the "Materials and Methods" section and was found to be minute in comparison to the ICG-PDR values computed by LiMON. 
for the disappearance of ICG because it remains stable for at least $4 \mathrm{~h}^{27}$

However, our results are consistent with the findings of Stehr et al. ${ }^{23}$ who described in a hyperdynamic porcine endotoxemia model an ICG-PDR increase although hepatic function assessed by measurement of biliary ICG excretion clearly decreased. Diffusion of the free or even the albumin-bound fraction of ICG to the interstitial space through an endothelial leak in the context of a perioperative systemic inflammatory response syndrome may explain the overestimation of ICG-PDR. ${ }^{28}$ Furthermore, as reported by other authors, considerable temporary redistribution of ICG in animal models into extrahepaticextravascular tissue may also assume importance in this context. $^{29,30}$ To explain the outcome in this study, therefore, we postulated a capillary leak with extravasation of protein-bound ICG into the interstitial space. ${ }^{31,32}$ Thus, we examined the correlation of ICG-PDR to (1) sequential postoperative serum albumin values, (2) differences in body weight before and after OLT, and (3) the post-OLT course of liquid balances. Neither albumin nor the clinical parameters correlated statistically with the ICG-PDR values. However, the difficulty of quantitatively assessing the capillary leak is well recognized. ${ }^{33}$

According to our findings, the precision of the correlation of ICG-PDR and functional hepatic reserve must be questioned. Our results are even more remarkable because hepatic perfusion was eliminated as a parameter influencing PDR. Overestimation of residual liver function may occur in situations with a possible capillary leak (e.g., sepsis, anaphylaxis, or perioperative systemic inflammatory response syndrome). Because misinterpretation of hepatic function is a crucial issue, especially in the small-for-size liver remnant scenarios with marginal residual hepatic reserves, a possible inaccuracy of up to $1.55 \% / \mathrm{min}$ on average has to be taken into account if ICG pulse spectrophotometry is used to determine functional hepatic reserve. It is important to recognize that this value corresponds to $31 \%$ of an ICG-PDR of $5.0 \% / \mathrm{min}$, which is considered the crucial cutoff point for a favorable outcome after major liver resection. ${ }^{19}$

\section{Conclusion}

During the anhepatic phase of OLT, ICG-PDR values were unexpectedly found to be considerably different from zero. Apart from hepatic perfusion and functional hepatic reserve, other factors seem to influence real-time ICGPDR determined by pulse spectrophotometry. These cofactors increase in importance with low ICG-PDR values and must be taken into account when determining the functional hepatic reserve in liver insufficiency or when assessing the minimally required hepatic mass during extended liver resection.

Acknowledgments We are indebted to Dr. H. Rieder, Institute of Anaesthesiology, University Hospital Bern, and Hans Saegesser, Institute of Clinical Pharmacology, University Hospital Bern for their skillful technical assistance.

\section{References}

1. Shoup M, Gonen M, D'Angelica M, Jarnagin WR, DeMatteo RP, Schwartz LH, Tuorto S, Blumgart LH, Fong Y. Volumetric analysis predicts hepatic dysfunction in patients undergoing major liver resection. J Gastrointest Surg 2003;7:325-330.

2. Leevy CM, Mendenhall CL, Lesko W, Howard MM. Estimation of hepatic blood flow with indocyanine green. J Clin Invest 1962;41:1169-1179.

3. Tygstrup N. Determination of the hepatic galactose elimination capacity after a single intravenous injection in man: the reproducibility and the influence of uneven distribution. Acta Physiol Scand 1963;58:162-172.

4. Paumgartner G. The handling of indocyanine green by the liver. Schweiz Med Wochenschr 1975;105:1-30.

5. Skak C, Keiding S. Methodological problems in the use of indocyanine green to estimate hepatic blood flow and ICG clearance in man. Liver 1987;7:155-162.

6. Kuntz H, Schregel W. Indocyanine green: evaluation of liver function-application in intensive care medicine. In Lewis F, Pfeiffer U, eds. Fiberoptics in Critical Care Monitoring. Berlin: Springer, 1990, pp 57-62.

7. Uusaro A, Ruokonen E, Takala J. Estimation of splanchnic blood flow by the Fick principle in man and problems in the use of indocyanine green. Cardiovasc Res 1995;30:106-112.

8. Ohwada S, Kawate S, Hamada K, Yamada T, Sunose Y, Tsutsumi $\mathrm{H}$, Tago K, Okabe T. Perioperative real-time monitoring of indocyanine green clearance by pulse spectrophotometry predicts remnant liver functional reserve in resection of hepatocellular carcinoma. Br J Surg 2006;93:339-346.

9. Gottlieb ME, Stratton HH, Newell JC, Shah DM. Indocyanine green. Its use as an early indicator of hepatic dysfunction following injury in man. Arch Surg 1984;119:264-268.

10. Kimura S, Yoshioka T, Shibuya M, Sakano T, Tanaka R, Matsuyama S. Indocyanine green elimination rate detects hepatocellular dysfunction early in septic shock and correlates with survival. Crit Care Med 2001;29:1159-1163.

11. Sakka SG, Reinhart K, Meier-Hellmann A. Prognostic value of the indocyanine green plasma disappearance rate in critically ill patients. Chest 2002;122:1715-1720.

12. Diaz S, Perez-Pena J, Sanz J, Olmedilla L, Garutti I, Barrio JM. Haemodynamic monitoring and liver function evaluation by pulsion cold system Z-201 (PCS) during orthotopic liver transplantation. Clin Transplant 2003;17:47-55.

13. Jochum C, Beste M, Penndorf V, Farahani MS, Testa G, Nadalin S, Malago M, Broelsch CE, Gerken G. Quantitative liver function tests in donors and recipients of living donor liver transplantation. Liver Transpl 2006;12:544-549.

14. Hori T, Iida T, Yagi S, Taniguchi K, Yamamoto C, Mizuno S, Yamagiwa K, Isaji S, Uemoto S. K(ICG) value, a reliable realtime estimator of graft function, accurately predicts outcomes in adult living-donor liver transplantation. Liver Transpl 2006; 12:605-613.

15. Shinohara H, Tanaka A, Kitai T, Yanabu N, Inomoto T, Satoh $S$, Hatano E, Yamaoka Y, Hirao K. Direct measurement of hepatic 
indocyanine green clearance with near-infrared spectroscopy: separate evaluation of uptake and removal. Hepatology 1996; 23:137-144.

16. Faybik P, Krenn CG, Baker A, Lahner D, Berlakovich G, Steltzer $\mathrm{H}$, Hetz H. Comparison of invasive and noninvasive measurement of plasma disappearance rate of indocyanine green in patients undergoing liver transplantation: a prospective investigatorblinded study. Liver Transpl 2004;10:1060-1064.

17. Sakka SG, Reinhart K, Meier-Hellmann A. Comparison of invasive and noninvasive measurements of indocyanine green plasma disappearance rate in critically ill patients with mechanical ventilation and stable hemodynamics. Intensive Care Med 2000;26:1553-1556.

18. Tsubono T, Todo S, Jabbour N, Mizoe A, Warty V, Demetris AJ, Starzl TE. Indocyanine green elimination test in orthotopic liver recipients. Hepatology 1996;24:1165-1171.

19. Inderbitzin D, Muggli B, Ringger A, Beldi G, Gass M, Gloor B, Uehlinger D, Regli B, Reichen J, Candinas D. Molecular absorbent recirculating system for the treatment of acute liver failure in surgical patients. J Gastrointest Surg 2005;9:1155-1161.

20. Schindl MJ, Redhead DN, Fearon KC, Garden OJ, Wigmore SJ. The value of residual liver volume as a predictor of hepatic dysfunction and infection after major liver resection. Gut 2005; 54:289-296.

21. Heemann U, Treichel U, Loock J, Philipp T, Gerken G, Malago M, Klammt S, Loehr M, Liebe S, Mitzner S, Schmidt R, Stange J. Albumin dialysis in cirrhosis with superimposed acute liver injury: a prospective, controlled study. Hepatology 2002;36:949-958.

22. Sen S, Williams R, Jalan R. Emerging indications for albumin dialysis. Am J Gastroenterol 2005;100:468-475.

23. Stehr A, Ploner F, Traeger K, Theisen M, Zuelke C, Radermacher $\mathrm{P}$, Matejovic M. Plasma disappearance of indocyanine green: a marker for excretory liver function? Intensive Care Med 2005;31: $1719-1722$

24. Fujita Y, Sakai T, Ohsumi A, Takaori M. Effects of hypocapnia and hypercapnia on splanchnic circulation and hepatic function in the beagle. Anesth Analg 1989;69:152-157.

25. Birnbaum J, Lehmann C, Taymoorian K, Krausch D, Wauer H, Grundling M, Spies C, Kox WJ. [The effect of dopexamine and iloprost on plasma disappearance rate of indocyanine green in patients in septic shock]. Anaesthesist 2003;52:1014-1019.

26. Pomier-Layrargues G, Huet PM, Villeneuve JP, Marleau D. Effect of portacaval shunt on drug disposition in patients with cirrhosis. Gastroenterology 1986;91:163-167.

27. Landsman ML, Kwant G, Mook GA, Zijlstra WG. Lightabsorbing properties, stability, and spectral stabilization of indocyanine green. J Appl Physiol 1976;40:575-583.

28. Ishihara H, Matsui A, Muraoka M, Tanabe T, Tsubo T, Matsuki A. Detection of capillary protein leakage by indocyanine green and glucose dilutions in septic patients. Crit Care Med 2000;28:620-626.

29. Ott P, Bass L, Keiding S. The kinetics of continuously infused indocyanine green in the pig. J Pharmacokinet Biopharm 1996;24:19-44.

30. Burczynski FJ, Pushka KL, Sitar DS, Greenway CV. Hepatic plasma flow: accuracy of estimation from bolus injections of indocyanine green. Am J Physiol 1987;252:H953-H962.

31. Ernest D, Belzberg AS, Dodek PM. Distribution of normal saline and $5 \%$ albumin infusions in septic patients. Crit Care Med 1999;27:46-50

32. Margarson MP, Soni NC. Changes in serum albumin concentration and volume expanding effects following a bolus of albumin 20\% in septic patients. Br J Anaesth 2004;92:821-826.

33. Ibla JC, Khoury J. Methods to assess tissue permeability. Methods Mol Biol 2006;341:111-117. 